\title{
Determination of Relationship between Dielectric Properties, Compressive Strength, and Age of Concrete with Rice Husk Ash Using Planar Coaxial Probe
}

\author{
Nawarat Piladaeng ${ }^{1}$, Niwat Angkawisittpan ${ }^{2}$, Sahalaph Homwuttiwong ${ }^{3}$ \\ ${ }^{1}$ Department of Electrical and Computer Engineering, Faculty of Engineering, Mahasarakham University, 44150, \\ Kantarawichai, Maha Sarakham, Thailand \\ ${ }^{2}$ Research Unit for Computational Electromagnetics and Optical Systems (CEMOS), Faculty of Engineering, \\ Mahasarakham University, 44150, Kantarawichai, Maha Sarakham, Thailand, niwat.a@msu.ac.th \\ ${ }^{3}$ Department of Civil Engineering, Faculty of Engineering, Mahasarakham University, 44150, Kantarawichai, \\ Maha Sarakham, Thailand
}

\begin{abstract}
This paper deals with an investigation of the dielectric properties of concretes that includes rice husk ash using a planar coaxial probe. The planar coaxial probe has a planar structure with a microstrip and coaxial features. The measurement was performed over the frequency range of $0.5-3.5 \mathrm{GHz}$, and concrete specimens with different percentages of rice husk ash were tested. The results indicated that the dielectric constant of the concretes was inversely proportional to the frequency, while the conductivity was proportional to the frequency. The dielectric constant decreased with the increasing age of the concrete at the frequency of $1 \mathrm{GHz}$. The conductivity of the concrete decreased with the increasing age of the concrete at the frequency of $3.2 \mathrm{GHz}$. In addition, the dielectric constant and the conductivity decreased when the compressive strength increased. It was also shown that the obtained dielectric properties of the concrete could be used to investigate the relationship between the compressive strength and age of the concrete. Moreover, there is an opportunity to apply the proposed probe to determine the dielectric properties of other materials.
\end{abstract}

Keywords: Planar coaxial probe, dielectric properties, rice husk ash, dielectric constant, conductivity.

\section{INTRODUCTION}

In agricultural countries, rice husk or rice hull is one of the major agricultural residues generated from the rice milling process. Rice husk is mostly reused as fuel in the milling plants, and the burnt rice husk is converted into ash, and called rice husk ash (RHA) [1]. Burning rice husk with a suitable combustion temperature provides ash that has up to $90 \%$ silica content [2]. RHA is a silica rich raw material that is considered to be a super pozzolan [3]. The chemical reaction analysis of RHA in concrete can be found in [4]. Fine ground RHA is widely used as a cement admixture in concrete to enhance the performance of the concrete, reuse the waste products, and reduce the environmental pollution and the cost of construction [4]. Many researchers have studied concrete with rice husk ash with respect to different aspects, i.e., the effect of the percentage variation, grinding time, surface area or particle size of RHA, the advantages and disadvantages of using RHA in concrete, the chloride content, and the effect of RHA on the physical properties (such as compressive strength) [5]-[10].
Besides focusing on the physical properties of concrete, the dielectric properties of concrete are important properties of concern because concrete is classified as a lossy dielectric material. The dielectric properties, such as complex relative permittivity, dielectric constant, dielectric loss factor, conductivity, reflection coefficient, and transmission coefficient, etc., are the electrical properties of the dielectric materials [11]. There are many methods to investigate the dielectric properties of materials [12]-[13]. However, the method that plays the most important role in the inspection of the dielectric properties is the microwave non-destructive testing (MNDT) method. The principle of MNDT is that an electromagnetic wave (EM) in the microwave frequency range is sent through the material under test (MUT), then the signal is reflected from and transmitted through the MUT, and it is collected and used to calculate the dielectric properties [14]. This method is used for determining the dielectric properties of many materials, for example, solutions, agricultural products, and biological materials, etc. [15]-[22]. Many studies have been conducted using MNDT to determine the dielectric properties of concretes 
with different mix proportions and ages to find the relationship between the dielectric constant, dielectric loss factor, and measuring frequencies, etc. In addition, there have been some research studies on the relationship between the dielectric properties and compressive strength [5], [23][25].

Although the dielectric properties of some materials and concretes have been studied, there have not been many studies related to other materials, such as concretes that use RHA as a supplementary cement material [2]-[5]. Moreover, few researchers have reported the relationship between the compressive strength and the dielectric properties of concrete [24]-[25].

In this paper, the dielectric properties of concretes with percentage variations in the RHA and different ages were investigated using a planar coaxial probe. The samples were measured for the reflection coefficients over the frequency range of $0.5-3.5 \mathrm{GHz}$, and then the dielectric properties of the samples were calculated to determine the relationship with the compressive strengths of the concretes. In addition, the dielectric properties of the samples were calculated to determine the relationship with the age of the concretes.

\section{Probe Design, PRobe CALIBRATION \& CALCUlAtion OF DIELECTRIC PROPERTIES}

\section{A. Probe design}

In this section, a microstrip transmission line and a coaxial structure were designed for the proposed planar coaxial probe.

The microstrip represents a transmission line fabricated on a printed circuit board (PCB). The microstrip consisted of two main conductive elements: strip (upper conductor) and ground plane (lower conductor), and a dielectric material: substrate, which was placed between the strip and ground plane as shown in Fig.1.

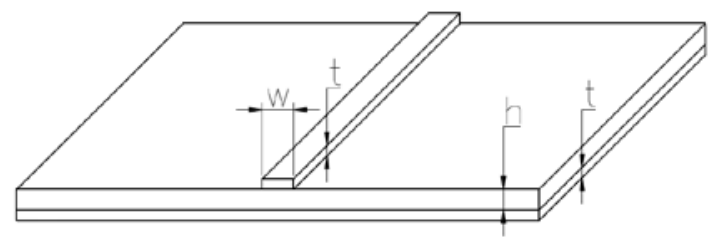

Fig.1. Structure of microstrip.

The coaxial structure consisted of two conductive parts: inner conductor and outer conductor, and a dielectric material that was put between both conductors, as presented in Fig. 2.

The design of the proposed probe, in Fig.3., was based on the basic parameters of the AD260A PCB: $\mathrm{Z}_{0}=50 \Omega$, $\mathrm{h}=$ $1 \mathrm{~mm}$, and $\varepsilon_{r 1}=2.6$. The required characteristic impedance of both designed structures was $50 \Omega$.

The microstrip and coaxial structures can be calculated using the formulas presented previously in [26]. The calculated effective dielectric permittivity and the strip width were 2.148 and $2.8 \mathrm{~mm}$, respectively. In addition, the shape of the designed probe was a square with sides of
$100 \mathrm{~mm}$ and strip length of $51.4 \mathrm{~mm}$. The ground plane was converted to the coaxial feature with $\varepsilon_{r 2}=1, \mathrm{a}=3 \mathrm{~mm}$, and $\mathrm{b}=6.9 \mathrm{~mm}$. The outer diameter of the outer conductor at the ground plane was $100 \mathrm{~mm}$. The central conductor was connected to the strip by a via-hole with a diameter of $2.8 \mathrm{~mm}$. The via-hole was filled with lead. A SMA connector was used to connect the proposed probe to a vector network analyzer (VNA).

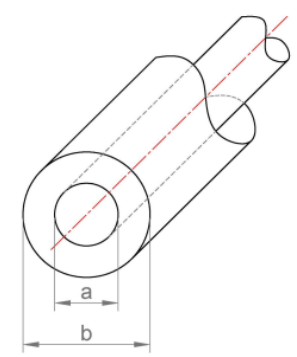

Fig.2. Structure of coaxial line.

The characteristic impedance of both designed structures was close to $50 \Omega$. This meant that the characteristic impedance of the probe was matched with the characteristic impedance of the SMA connector and the Vector Network Analyzer (VNA), which also had the $50 \Omega$ characteristic impedance. In addition, concrete has been recognized as a dielectric material [11]. Therefore, the proposed probe can be used to measure the reflection coefficient, which can be used to calculate the dielectric properties of the concrete.

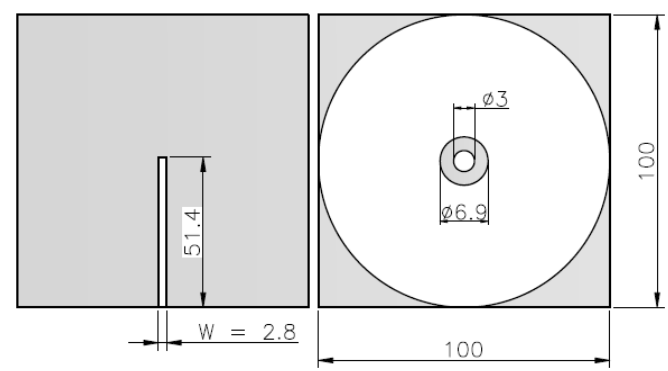

a)

b)

Fig.3. a) Strip side and b) ground plane side of proposed planar coaxial probe (unit: $\mathrm{mm}$ ).

B. Probe calibration and calculation of dielectric properties

The dielectric properties of any materials can be determined by placing the ground plane of the probe on the MUT. A microwave signal from the VNA is sent through the MUT and then a signal is reflected from the MUT. The signal is collected and used to calculate the dielectric properties in terms of a complex relative permittivity.

The complex relative permittivity $\left(\varepsilon_{r}\right)$ was focused as one of the dielectric properties. The complex relative permittivity is shown in (1), [27]-[28]:

$$
\varepsilon_{r}=\varepsilon_{r}^{\prime}-j \varepsilon_{r}^{\prime \prime}
$$


where $\varepsilon_{r}^{\prime}$ is the real part of the complex relative permittivity and $\varepsilon_{r}$ is its imaginary part. The real part, called the dielectric constant, is a factor that informs about the stored energy in a material. The imaginary part, called the dielectric loss factor, indicates the loss of energy in the material.

The conductivity of materials can be given in terms of the imaginary part of the complex relative permittivity as follows [25]:

$$
\sigma=\varepsilon_{0} \varepsilon_{r} \omega=\varepsilon_{0} \varepsilon_{r} 2 \pi f
$$

where $\sigma$ is the conductivity $(\mathrm{S} / \mathrm{m}), \varepsilon_{0}$ is the permittivity of free space $\left(8.854 \times 10^{-12} \mathrm{~F} / \mathrm{m}\right)$, $\omega$ is the angular frequency of the EM wave ( $\mathrm{rad} / \mathrm{s})$, and $f$ is the frequency $(\mathrm{Hz})$.

The reflection coefficients of reference and unknown materials are expressed in terms of the known complex relative permittivity of the reference materials, which were obtained from previous studies [27], [29]-[31], and calculation for the complex relative permittivity of the unknown material can be defined as in (3), [29], [32]:

$$
\frac{\left(\varepsilon_{S}-\varepsilon_{A}\right)\left(\varepsilon_{B}-\varepsilon_{C}\right)}{\left(\varepsilon_{S}-\varepsilon_{B}\right)\left(\varepsilon_{C}-\varepsilon_{A}\right)}=\frac{\left(\Gamma_{S}-\Gamma_{A}\right)\left(\Gamma_{B}-\Gamma_{C}\right)}{\left(\Gamma_{S}-\Gamma_{B}\right)\left(\Gamma_{C}-\Gamma_{A}\right)}
$$

where $\varepsilon_{A}, \varepsilon_{B}$, and $\varepsilon_{C}$ are the known complex relative permittivities of three reference materials, $\varepsilon_{S}$ is the complex relative permittivity of an unknown material, and $\Gamma_{\mathrm{A}}, \Gamma_{\mathrm{B}}, \Gamma_{\mathrm{C}}$, and $\Gamma_{\mathrm{S}}$ are the reflection coefficients of those three references and unknown materials, respectively.

The probe was calibrated by measuring the reflection coefficients of the reference materials at room temperature $\left(25^{\circ} \mathrm{C}\right)$. In this calibration, the reference materials were ethanol, distilled water, methanol, and air, for which their complex relative permittivities were expressed by the ColeCole equation as indicated in (4), [33]-[34]:

$$
\varepsilon_{r}=\varepsilon_{\infty}+\frac{\varepsilon_{S}-\varepsilon_{\infty}}{1+(j \omega \tau)^{1-\alpha}}
$$

where $\varepsilon_{\infty}$ is the relative permittivity at an infinite frequency, $\varepsilon_{S}$ is the relative permittivity at a static frequency, $\omega$ is the angular frequency ( $\mathrm{rad} / \mathrm{s}), \tau$ is the relaxation time, and $\alpha$ is the distribution parameter of the relaxation time. The Cole-Cole parameters of the references are illustrated in Table 1.

\section{CONCRETE SPECIMENS \& MEASUREMENT SETUP}

\section{A. Concrete specimens}

In the experiment, a standard from the American Concrete Institute (ACI) was used as the reference in the concrete mix design of the cylindrical test specimens. The dimensions of the specimens were $\varnothing 10 \times 20 \mathrm{~cm}$. The main ingredients of the specimens were cement, RHA, water, sand, and gravel. Ordinary Portland cement type I (OPC type I), produced under Thailand Industrial Standard (TIS. 80-2517), was used in this test. The replacement of the OPC by the RHA was at $0,10,20$, and $30 \%$ by weight with the same water-binder (W/B) ratio of 0.45 . Both the compressive strength test and the MNDT test using the proposed planar coaxial probe were conducted at concrete ages of 7, 28, and 90 days. All specimens were measured at room temperature $\left(25^{\circ} \mathrm{C}\right)$. The specimens were measured for the reflection coefficients six times at random positions. The specimens were cured in water and then brought out of the water and kept under room conditions for 24 hours before testing. The mix proportions and compressive strengths of the concretes are illustrated in Table 2. and Table 3., respectively.

Table 1. Cole-Cole parameters of reference materials.

\begin{tabular}{|c|c|c|c|c|c|}
\hline \multirow{2}{*}{ Replacement } & \multicolumn{5}{|c|}{ Mix proportion $\left(\mathrm{kg} / \mathrm{m}^{3}\right)$} \\
\hline & Cement & RHA & Water & Sand & Gravel \\
\hline $0 \%$ & 450 & 0 & 157.5 & 874 & 1,080 \\
\hline $10 \%$ & 315 & 35 & 157.5 & 874 & 1,080 \\
\hline $20 \%$ & 280 & 70 & 157.5 & 874 & 1,080 \\
\hline $30 \%$ & 245 & 105 & 157.5 & 874 & 1,080 \\
\hline
\end{tabular}

\begin{tabular}{|c|c|c|c|c|}
\hline \multirow{2}{*}{ Reference materials } & \multicolumn{4}{|c|}{ Cole-Cole parameters } \\
\cline { 2 - 5 } & $\varepsilon_{\infty}$ & $\varepsilon_{S}$ & $\tau$ (ps) & $\alpha$ \\
\hline Ethanol [29] & 3.91 & 21.4 & 980.39 & 0.03 \\
\hline Distilled water [30] & 4.22 & 78.6 & 8.8 & 0.013 \\
\hline Methanol [31] & 4.45 & 33.7 & 49.5 & 0.036 \\
\hline Air [27] & \multicolumn{5}{|c|}{$\varepsilon=1$} \\
\hline
\end{tabular}

Table 2. Mix proportions of concretes.

Table 3. Compressive strengths of concretes.

\begin{tabular}{|c|c|c|c|}
\hline \multirow{2}{*}{ Replacement } & \multicolumn{3}{|c|}{ Compressive strength $\mathbf{( k g / \mathbf { c m } ^ { 2 } )}$} \\
\cline { 2 - 4 } & $\mathbf{7}$ days & $\mathbf{2 8}$ days & $\mathbf{9 0}$ days \\
\hline $0 \%$ & 372.62 & 424.84 & 503.19 \\
\hline $10 \%$ & 203.82 & 282.80 & 321.87 \\
\hline $20 \%$ & 174.10 & 203.82 & 243.31 \\
\hline $30 \%$ & 129.51 & 163.06 & 194.48 \\
\hline
\end{tabular}

\section{B. Measurement setup}

The MNDT system to measure the dielectric properties of the concrete specimens consisted of a planar coaxial probe, an Agilent E5071B ENA series network analyzer, a support stand, and a computer. The measurement setup is illustrated in Fig.4. The fabricated probe is presented in Fig.5. and Fig.6.

The experiment was conducted at room temperature $\left(25^{\circ} \mathrm{C}\right)$. The probe was held by the stand. Its front side was placed on a cross section area of a specimen. The EM wave from the network analyzer was sent toward the specimen and then the reflection coefficient $(\Gamma)$ reflected from the specimen was collected. Air, distilled water, and methanol were used as the standard materials for calibration, 
and the reflection coefficients of those materials were measured. The measured reflection coefficients were used for calculating the dielectric properties in terms of a complex relative permittivity. A dielectric constant was obtained from the real part of the complex relative permittivity, and the conductivity was calculated from the imaginary part of the complex relative permittivity using (2). After that, the calculated dielectric constants and conductivities were analyzed to find the correlations with the compressive strengths of the concrete specimens.

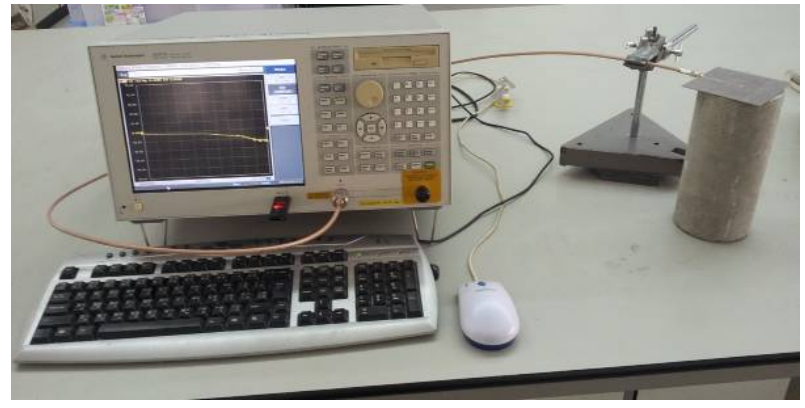

Fig.4. Measurement setup for investigating dielectric properties of concrete specimens.

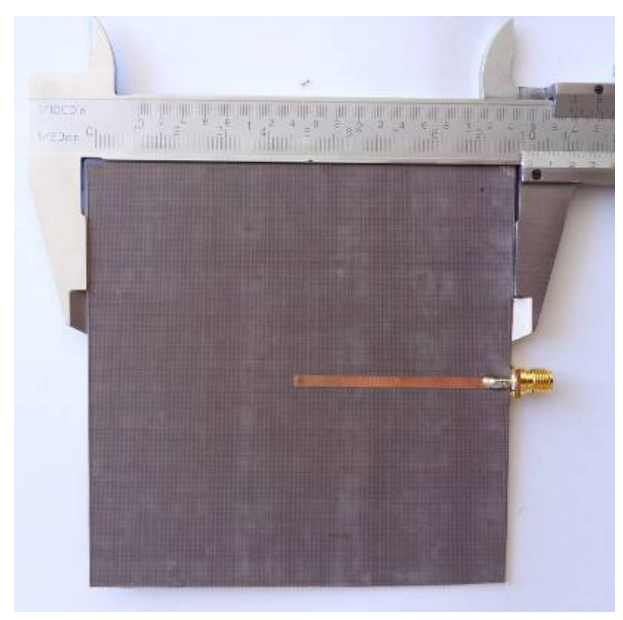

Fig.5. Back view of fabricated probe.

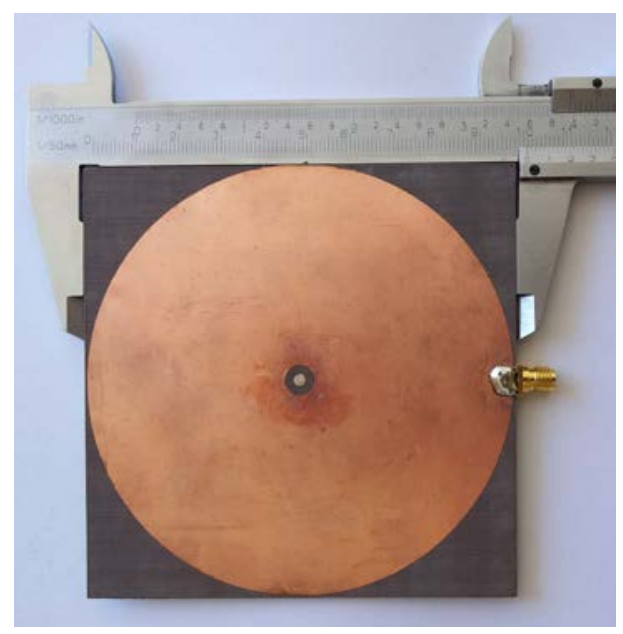

Fig.6. Front view of fabricated probe.

\section{EXPERIMENTAL RESULTS}

In this section, the experiment was performed by following the measurement setup in section 3. There were 12 sets of cylindrical samples, as listed in Table 2. and Table 3. The test was performed over the same frequency range of $0.5-3.5 \mathrm{GHz}$. The measured reflection coefficients were collected and the dielectric properties were calculated. The results are illustrated according to the complex relative permittivities and the conductivities while varying the measurement frequencies and the relationship between the concrete age, compressive strength, and dielectric properties.

The results from the measurements of the concrete with different percentages of RHA at the ages of 7, 28, and 90 days indicated that the obtained complex relative permittivities and the conductivities varied with changing frequency. At the age of 90 days, all obtained dielectric constants decreased with increasing frequency, while the conductivities increased as shown in Fig.7. and Fig.8.

In addition, the concrete with RHA at 30 and $0 \%$ by weight provided the highest and lowest dielectric properties, respectively.

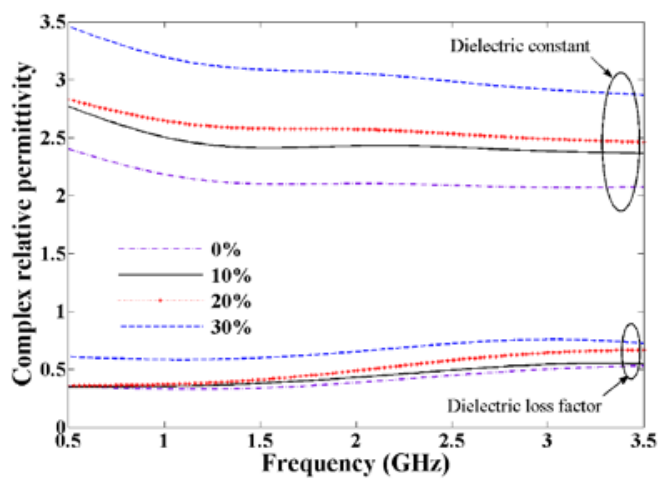

Fig.7. Results of complex relative permittivities of concrete with different percentages of RHA at age of 90 days versus frequencies.

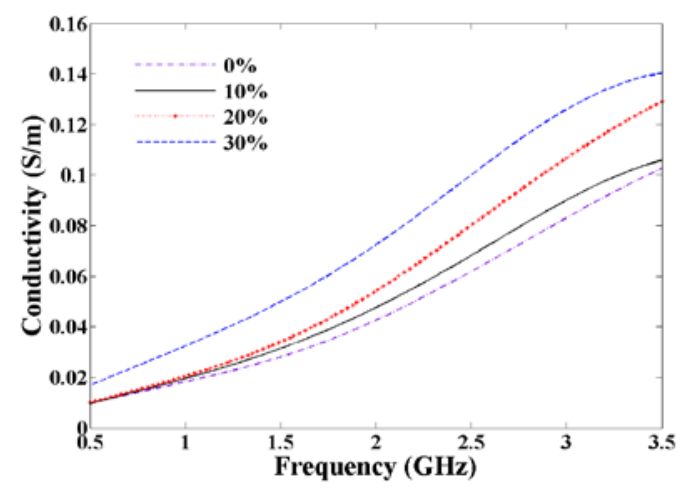

Fig.8. Results of conductivities of concrete with different percentages of RHA at age of 90 days versus frequencies.

Fig.9. shows the results of the dielectric constants versus the concrete age at different percentages of RHA at the frequency of $1 \mathrm{GHz}$, and Fig.10. illustrates the concrete conductivities versus age at the frequency of $3.2 \mathrm{GHz}$. The results indicated that the dielectric constants and 
conductivities decreased with increasing age of the concrete. These variations were caused by the hydration and evaporation in the concrete. A concrete usually contains water as one of the main ingredients, and the dielectric constant of water is higher than the other ingredients of the concrete. When the age of the concrete increased, the hydration and evaporation caused a reduction of the free water in the concrete. This caused a decrease in the dielectric constant and the conductivity.

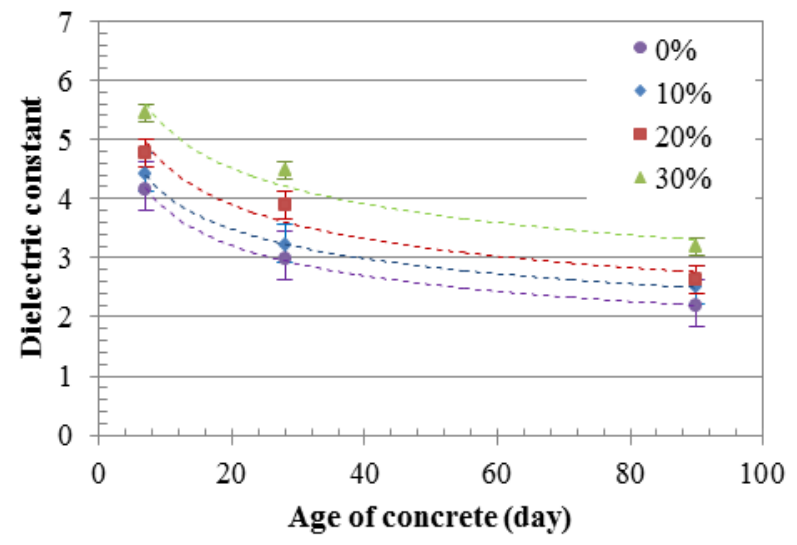

Fig.9. Dielectric constants of concrete with different percentages of RHA at frequency of $1 \mathrm{GHz}$ versus concrete age.

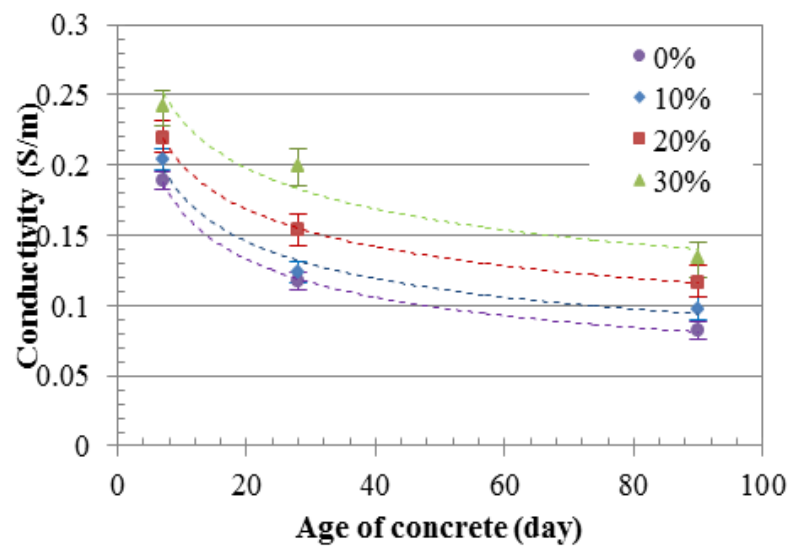

Fig.10. Conductivities of concrete with different percentages of RHA at frequency of $3.2 \mathrm{GHz}$ versus concrete age.

In a simple regression analysis, it was found that the dielectric constants at the frequency of $1 \mathrm{GHz}$ and the conductivities at the frequency of $3.2 \mathrm{GHz}$ had power-law relationships with the concrete age. The power-law relationships and correlation coefficients of the data plotted in Fig.9. and Fig.10. can be defined as follows:

$$
\begin{array}{ll}
\mathrm{D}_{0 \%}=6.8099 \mathrm{~A}^{-0.252}, & \mathrm{R}^{2}=0.9989 \\
\mathrm{D}_{10 \%}=6.6563 \mathrm{~A}^{-0.224}, & \mathrm{R}^{2}=0.9073 \\
\mathrm{D}_{20 \%}=7.7575 \mathrm{~A}^{-0.23}, & \mathrm{R}^{2}=0.9183 \\
\mathrm{D}_{30 \%}=8.3018 \mathrm{~A}^{-0.208}, & \mathrm{R}^{2}=0.9544 \\
\mathrm{C}_{0 \%}=0.3543 \mathrm{~A}^{-0.328}, & \mathrm{R}^{2}=0.9993
\end{array}
$$

$$
\begin{array}{ll}
\mathrm{C}_{10 \%}=0.3475 \mathrm{~A}^{-0.29}, & \mathrm{R}^{2}=0.9756 \\
\mathrm{C}_{20 \%}=0.3549 \mathrm{~A}^{-0.249}, & \mathrm{R}^{2}=0.9995 \\
\mathrm{C}_{30 \%}=0.3928 \mathrm{~A}^{-0.229}, & \mathrm{R}^{2}=0.9391
\end{array}
$$

where D is the averaged dielectric constant, $\mathrm{C}$ is the averaged conductivity, $\mathrm{A}$ is the age of the concrete, and $\mathrm{R}$ is the correlation coefficient. The subscripts following $\mathrm{D}$ and $\mathrm{C}$ refer to the percentages of RHA at $0,10,20$, and $30 \%$ by weight.

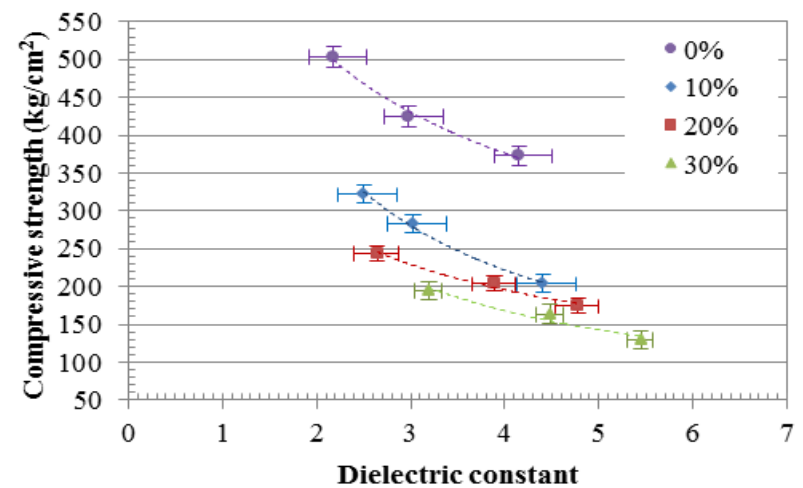

Fig.11. Relationship between compressive strengths and dielectric constants of concrete with different percentages of RHA at frequency of $1 \mathrm{GHz}$.

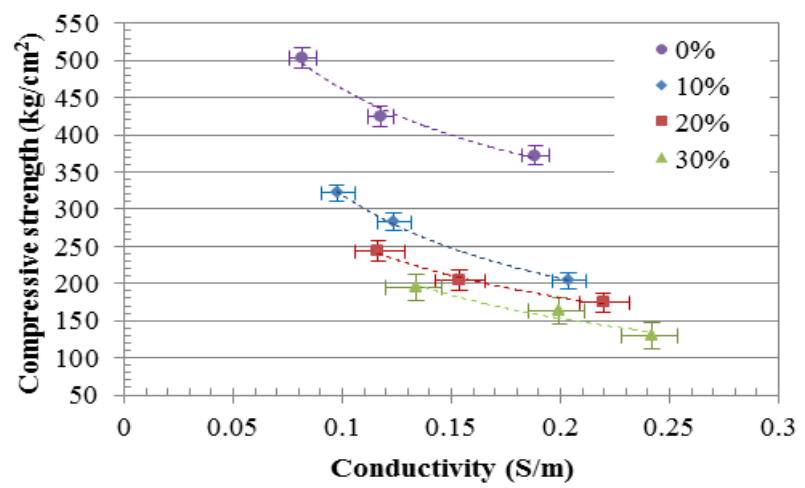

Fig.12. Relationship between compressive strengths and conductivities of concrete with different percentages of RHA at frequency of $3.2 \mathrm{GHz}$.

The compressive strengths of the specimens were compared to the obtained dielectric constants and conductivities of the concrete with the different percentages of RHA in Table 3. The relationships between the compressive strengths and the dielectric constants at the frequency of $1 \mathrm{GHz}$ are illustrated in Fig.11., and the relationships between the compressive strengths and the conductivities at the frequency of $3.2 \mathrm{GHz}$ are shown in Fig.12. As seen in Table 3., the compressive strengths increased with the concrete age. Moreover, the compressive strengths of the concrete with RHA at 0 and $30 \%$ were the highest and lowest, respectively. From Fig.11. and Fig.12., the results showed that the dielectric constants and conductivities of the concrete were inversely proportional to the compressive strengths. 
The dielectric constants at the frequency of $1 \mathrm{GHz}$ and conductivities at the frequency of $3.2 \mathrm{GHz}$ had power-law relationships with the compressive strengths of the concrete. The power-law relationships and correlation coefficients of the data plotted in Fig.11. and Fig.12. are expressed as follows:

$$
\begin{array}{ll}
\mathrm{S}_{\mathrm{D} 0 \%}=717.91 \mathrm{D}^{-0.466}, & \mathrm{R}^{2}=0.992 \\
\mathrm{~S}_{\mathrm{D} 10 \%}=686.92 \mathrm{D}^{-0.816}, & \mathrm{R}^{2}=0.997 \\
\mathrm{~S}_{\mathrm{D} 20 \%}=419.62 \mathrm{D}^{-0.551}, & \mathrm{R}^{2}=0.9801 \\
\mathrm{~S}_{\mathrm{D} 30 \%}=465.79 \mathrm{D}^{-0.735}, & \mathrm{R}^{2}=0.9477 \\
\mathrm{~S}_{\mathrm{C} 0 \%}=203.57 \mathrm{C}^{-0.355}, & \mathrm{R}^{2}=0.9779 \\
\mathrm{~S}_{\mathrm{C} 10 \%}=75.516 \mathrm{C}^{-0.626}, & \mathrm{R}^{2}=0.9985 \\
\mathrm{~S}_{\mathrm{C} 20 \%}=78.024 \mathrm{C}^{-0.524}, & \mathrm{R}^{2}=0.989 \\
\mathrm{~S}_{\mathrm{C} 30 \%}=53.774 \mathrm{C}^{-0.649}, & \mathrm{R}^{2}=0.9256
\end{array}
$$

where $\mathrm{S}$ is the averaged compressive strength of the concrete, D is the measured dielectric constant, C is the measured conductivity, and $\mathrm{R}$ is the correlation coefficient. The subscripts following $\mathrm{S}$ refer to the percentages of RHA at $0,10,20$, and $30 \%$ by weight.

The results indicated that the compressive strength of the concrete can be evaluated by using the dielectric properties measured using the planar coaxial probe. This supports the feasibility of using the planar coaxial probe as a MNDT tool for testing the compressive strength.

\section{CONCLUSIONS}

In this paper, a microwave test using a planar coaxial probe to investigate the dielectric properties of concrete with RHA has been reported. The microstrip and coaxial structures have been considered to be important features of the proposed probe. The planar coaxial probe was designed, fabricated, and calibrated. The experiments were performed by following the measurement setup. The microwave test using the proposed probe works properly to determine the dielectric constants and conductivities of the concrete. The results show that:

1. The dielectric constants of the concrete decreased with increasing frequency, while the conductivities of the concrete increased when the frequency increased. The concrete in which the OPC was replaced by RHA at 30 and $0 \%$ by weight provided the highest and lowest averaged values of the dielectric constant and conductivity, respectively.

2. The dielectric constants and conductivities decrease with increasing age of the concrete. In addition, both the dielectric constant and the conductivity had power-law relationships with the age of the concrete.

3. The dielectric constants and conductivities of the concrete were inversely proportional to the compressive strengths. The compressive strengths of the concretes with RHA at 0 and $30 \%$ were the highest and lowest, respectively. Both the dielectric constant and the conductivity had power-law relationships with the compressive strength of the concrete.

The results indicated that the proposed probe could be used to measure the dielectric properties of concrete, and the obtained dielectric properties could be used to determine the relationship with the compressive strength and age of the concrete. Therefore, it is feasible to develop the planar coaxial probe for the measurement of the dielectric properties, and to apply this proposed system to inspect the relationship with the compressive strength and age of the concrete in other mix proportions or to investigate the dielectric properties of other interesting materials.

\section{ACKNOWLEDGMENT}

This work was financially supported by The Thailand Research Fund (MRG5580057) and The Research Unit for Computational Electromagnetics and Optical Systems (CEMOS), the Faculty of Engineering, Mahasarakham University, Thailand. The authors would like to thank Prof. Dr. Prinya Chindaprasirt, The Sustainable Infrastructure Research and Development Center, Faculty of Engineering, Khon Kaen University, Thailand for valuable advice.

\section{REFERENCES}

[1] Kumar, A., Mohanta, K., Kumar, D., Parkash, O. (2012). Properties and industrial applications of rice husk: A review. International Journal of Emerging Technology and Advanced Engineering, 2 (10), 86-90.

[2] Rao, P.P., Kumar, A.P., Singh, B.B. (2014). A study on use of rice husk ash in concrete. International Journal of Education and Applied Research, 4 (2), 7581.

[3] Akeke, G.A., Ephraim, M.E., Akobo, I.Z.S., Ukpata, J.O. (2013). Structural properties of rice husk ash concrete. International Journal of Engineering and Applied Sciences, 3 (3), 57-62.

[4] Dabai, M.U., Muhammad, C., Bagudo, B.U., Musa, A. (2009). Studies on the effect of rice husk ash as cement admixture. Nigerian Journal of Basic and Applied Science, 17 (2), 252-256.

[5] Habeeb, G.A., Mahmud, H.B. (2010). Study on properties of rice husk ash and its use as cement replacement material. Materials Research, 13 (2), 185190.

[6] Kartini, K. (2011). Rice husk ash - pozzolanic material for sustainability. International Journal of Applied Science and Technology, 1 (6), 169-178.

[7] Kusbiantoro, A., Nuruddin, M.F., Shafiq, N., Qazi, S.A. (2012). The effect of microwave incinerated rice husk ash on the compressive and bond strength of fly ash based geopolymer concrete. Construction and Building Materials, 36, 695-703.

[8] Bui, L.A.T., Chen, C.T., Hwang, C.L., Wu, W.S. (2012). Effect of silica forms in rice husk as on the properties of concrete. International Journal of Minerals, Metallurgy and Materials, 19 (3), 252-258.

[9] Karim, M.R., Zain, M.F.M., Jamil, M., Lai, F.C., Islam, M.N. (2012). Strength of mortar and concrete as influenced by rice husk ash: A review. Word Applied Sciences Journal, 19 (10), 1501-1513. 
[10] Krishna, R.N. (2012). Rice husk ash - an ideal admixture for concrete in aggressive environments. In 37th Conference on Our World in Concrete \& Structures, 29-31 August 2012, Singapore.

[11] Jamil, M., Hassan, M.K., Al-Mattarneh, H.M.A., Zain, M.F.M. (2013). Concrete dielectric properties investigation using microwave nondestructive techniques. Material and Structures, 46, 77-87.

[12] You, K.Y., Abbas, Z., Malek, M.F.A., Cheng, E.M. (2014). Non-destructive dielectric measurements and calibration for thin materials using waveguide-coaxial adaptors. Measurement Science Review, 14 (1), 16-24.

[13] Roj, J., Cichy, A. (2015). Method of measurement of capacitance and dielectric loss factor using artificial neural networks. Measurement Science Review, 15 (3), 127-131.

[14] Industrial Applications and Chemistry Section. (2002). Guidebook on Non-destructive Testing of Concrete Structures. Vienna, Austria: International Atomic Energy Agency.

[15] Cheng , E.M., Fareq, M., Shahriman, A.B., Afendi, M., Zulkarnay, Z., Khor, S.F., Liyana, Z., Nashrul, F. M.N., Tan, W.H., Noorpi, N.S.M., Mukhtar, N.M., Othman, M. (2014). Development of low cost microwave detection system for salinity and sugar detection. International Journal of Mechanical \& Mechatronics Engineering, 14 (5), 59-71.

[16] Vrba, J. (2013). Coaxial reflection probe for measurements of temperature and frequency dependent dielectric-properties of low-loss liquids. In Progress in Electromagnetics Research Symposium Proceedings, 12-15 August 2013, Stockholm, Sweden. PIERS, 1091-1094.

[17] Guo, W.C., Nelson, S.O., Trabelsi, S., Kays, S.J. (2007). 10-1800-MHz dielectric properties of fresh apples during storage. Journal of Food Engineering, 83 (4), 562-569.

[18] Brinley, T.A., Truong, V.D., Coronel, P., Simunovic, J., Sandeep, K.P. (2008). Dielectric properties of sweet potato purees at $915 \mathrm{MHz}$ as affected by temperature and chemical composition. International Journal of Food Properties, 11 (1), 158-172.

[19] Yeow, Y.K., Abbas, Z., Khalid, K. (2010). Application of microwave moisture sensor for determination of oil palm fruit ripeness. Measurement Science Review, 10 (1), 7-14.

[20] Faktorová, D. (2007). Complex permittivity of biological materials measurement at microwave frequencies. Measurement Science Review, 7 (2-2), 12-15.

[21] Angkawisittpan, N., Manasri, T. (2012). Determination of sugar content in sugar solutions using interditital capacitor sensor. Measurement Science Review, 12 (1), 8-13.

[22] Harnsoongnoen, S., Siritaratiwat, A. (2015). Electrical and absorption properties of fresh cassava tubers and cassava starch. Journal of Instrumentation, 10, 1-12.
[23] Zhong, Y.H., Zhang, B., Shi, W.B., Wang, T. (2012). Experimental research on relationships between dielectric constant of cement concrete materials and measuring frequency. In 14th International Conference on Ground Penetrating Radar, 4-8 June 2012, Shanghai, China, 403-406.

[24] Filali, B., Boone, F., Rhazi, J., Ballivy, G. (2008). Design and calibration of a large open-ended coaxial probe for the measurement of the dielectric properties of concrete. IEEE Transactions and Microwave Theory and Techniques, 56 (10), 2322-2328.

[25] Kwon, S.J., Feng, M.Q., Park, T.W., Na, U.J. (2009). An experimental study on evaluation of compressive strength in cement mortar using averaged electromagnetic properties. International Journal of Concrete Structures and Materials, 3 (1), 25-32.

[26] Chen, L.F., Ong, C.K., Neo, C.P., Varadan, V.V., Varadan, V.K. (2004). Microwave Electronics: Measurement and Materials Characterization. John Wiley and Sons, 288-290.

[27] Komarov, V., Wang, S., Tang, J. (2005). Permittivity and measurement. In Encyclopedia of RF and Microwave Engineering. John Wiley \& Sons, 36933711.

[28] Agilent Technologies. (2006). Basics of measuring the dielectric properties of materials: Application note. http://www3.imperial.ac.uk.

[29] Kang, B., Park, J.H., Cho, J., Kwon, K., Lim, S., Yoon, J., Cheon, C., Kim, Y.K., Kwon, Y. (2005). Novel low-cost planar probes with broadside apertures for nondestructive dielectric measurement of biological materials at microwave frequencies. IEEE Transaction on Microwave Theory and Techniques, 53 (1), 134-143.

[30] Nyshadham, A., Sibbald, C.L., Stuchly, S.S. (1992). Permittivity measurements using open-ended sensors and reference liquid calibration - an uncertainty analysis. IEEE Transections on Microwave Theory and Techniques, 40 (2), 305-314.

[31] Blackham, D.V., Pollard, R.D. (1997). An improved technique for permittivity measurements using a coaxial probe. IEEE Transaction on Instrumentation and Measurement, 46 (5), 1093-1099.

[32] Kang, B., Cho, J., Cheon, C., Kwon, Y. (2004). A planar-type probe with a coaxial aperture for nondestructive complex permittivity measurement of biological materials up to $30 \mathrm{GHz}$. In IEEE MTT-S International Microwave Symposium Digest, 6-11 June 2004. IEEE, Vol. 3, 1441-1444.

[33] Buff, P.M., Steer, M.B., Lazzi, G. (2006). Cole-Cole dispersion models for aqueous gelatin-syrup dielectric composites. IEEE Transactions on Geoscience and Remote Sensing, 44 (2), 351-355.

[34] Buckley, F., Maryott, A.A. (1958). Tables of Dielectric Dispersion Data for Pure Liquids and Dilute Solutions. National Bureau of Standards Circular 589, United States Department of Commerce.

Received June 23, 2015. Accepted January 28, 2016. 